\title{
Acne Vulgaris: A Patient and Physician's Experience
}

Nicola I. Espinosa · Philip R. Cohen

Received: September 3, 2019 / Published online: November 7, 2019

(C) The Author(s) 2019

\section{ABSTRACT}

In this article, the first coauthor, a young woman with acne vulgaris, shares her experience with the condition; she not only describes the clinical presentation and the eventual successful treatment of her acne, but also the emotional consequences that this skin disorder caused. The second coauthor, the patient's dermatologist, reviews some of the features of acne vulgaris: morphologic manifestations, pathogenesis, and treatment options. He also summarizes the patient's response to isotretinoin therapy. In addition, he reveals his subsequent enlightenment regarding the acne-

The article is part of the Topical Collection on Patient and Physician Perspectives.

Enhanced Digital Features To view enhanced digital features for this article go to https://doi.org/10.6084/ m9.figshare.9959003.

\section{N. I. Espinosa}

College of Sciences, San Diego State University, San Diego, CA, USA

P. R. Cohen $(\varangle)$

San Diego Family Dermatology, National City, CA, USA

e-mail: mitehead@gmail.com

P. R. Cohen

Department of Dermatology, Touro University

California College of Osteopathic Medicine, Vallejo,

CA, USA related non-dermatologic effects that the patient experienced and the significant improvement of her self-image that occurred following the successful treatment of her acne.

Keywords: Acid; Acutane; Acne vulgaris; 13cis-retinoic; Isotretinoin; Experience; Patient; Physician; Trans-retinoic; Treatment

\section{Key Summary Points}

Acne vulgaris, usually referred to as acne, is an inflammatory condition of the skin that affects the pilosebaceous follicle.

The pathogenesis of acne is multifactorial: bacterial colonization (by Propionibacterium acnes), follicular hyperkeratinization, inflammation, and sebum production.

The development of acne is influenced by diet; it is associated with the consumption of saturated fats, dairy products and foods with a high glycemic index.

Topical therapies, systemic antibiotics, hormonal agents, isotretinoin and miscellaneous therapies may be incorporated in the management of acne.

Isotretinoin may be used as the first-line treatment for severe nodulocystic acne. 


\section{PATIENT'S EXPERIENCE}

Cystic acne is a debilitating condition that had a significant impact on my life. So, when my family doctor finally referred me to a dermatologist to see whether I could be treated with isotretinoin (also referred to as 13-cis-retinoic acid), I was absolutely ready.

As superficial as it sounds, the issues I had with my outward appearance ran deep. It wasn't "just acne"; it was everything to me for 6 years. And as silly as it sounds, I think I identified with the problems I had with my acne. It was all I could see when I looked in the mirror and it reflected in my low self-esteem, manifested in the opportunities I was too afraid or ashamed to take, in how I neglected or avoided others, and the unnecessary anxiety and disappointment with myself.

I had acne when my family and I still lived in Hawaii where I was raised and attended traditional public schools, when we moved to Idaho where I attended an online school for a year before returning to traditional schooling, and when we made our last move to California. Throughout these moves and my teen years, I had been seen by family doctors in my local town, and city-based dermatologists in the nearby cities; however, nothing they gave me ever worked. After arriving in California, at 16 years of age, my acne became even worse.

Since I was 14 years old, I had tested so many treatments. I had tried topical medications [such as adapalene, benzoyl peroxide, clindamycin, a combination of adapalene and benzoyl peroxide, a combination of clindamycin and benzoyl peroxide, erythromycin and tretinoin (also known as trans-retinoic acid)], oral medications [such as antibiotics (doxycycline and minocycline) and a combination oral contraceptive pill containing ethinyl estradiol and norgestimate] and an assortment of facial cleansers, moisturizers, creams, and serums from various companies: Mary Kay, A.C. Care Bee's, Lancôme, Clean \& Clear, Cetaphil, Aveeno, Neutrogena, EltaMD, and Shiseido. I had tried it all - as gels, creams, lotions, and ointments at different percentages and dosages, with different combinations, with different regimens, and at different times of my life.

Like many teenagers, I was already very selfconscious and cared about how I looked. However, I observed no improvement in my skin regardless of what I did, or how much money I spent, or even where I was, or how much time had passed. This led to both physical and psychosocial effects on me.

I was so exhausted. I felt hopeless and, truthfully, ugly. I didn't want anyone to look at me, so I did everything I could to hide and direct any attention away from me; however, I still felt that people were only focusing on my acne when they interacted with me. I also felt like I was incompetent at everything.

Growing up, as a teenager, was difficult; however, it became even more challenging with my skin. I usually chose to work alone. I quietly embraced my self-pity, all under the guise of "independence."

In addition, I had spent a lot of time staying away from most people and trying to avoid new activities. In all the schools I went to, I never joined a club or openly participated in class or even talked to anyone (not even during online school!). Assemblies, group projects, presentations, and hands-on work (such as laboratory sessions) were the hardest activities for me to deal with.

In my first year and a half of community college, starting in August 2017, I noticed my acne less often but cared about it much more. Whenever I did have the time to notice what was on my face, I immediately felt this urge to go home. Some early mornings I would wake up with dots of dried blood on my face from pimples that popped the night before; it was so physically and emotionally painful. I dreaded waking up to this face.

During the drive to school, when I was looking in the mirror, the sunlight would highlight the horrendous red bumps scattered all throughout my face - a big one on my nose, tiny ones behind my nose, many spread out on my cheeks and dotting my forehead and chin, even some on my temples and a couple within my eyebrow hairs. If one disappeared, another one would show up. It looked as if the pimples 
were running out of room on my face but always managed to find a spot (Figs. 1 and 2).

Then, early in December 2018, I saw my family doctor. He works at a clinic near my home; he has seen me multiple times since I had moved to California, primarily for acne checkups and prescription refills. At this visit, he finally said, "I think it's time for you to go on isotretinoin, but I cannot prescribe it to you. I am going to refer you to a dermatologist."

I had heard so much about this (in)famous medicine by reading online and watching people talk about it on YouTube. I knew it was used as a last resort and that it had a long list of serious side effects. Some of the side effects may have been exaggerated or rare, but the anecdotes about them were convincing and scary. However, I didn't care how isotretinoin would affect me if it worked to treat my acne. I knew it was extremely effective in not only helping with acne, but also for clearing it; that was all I needed to know.

By mid-January 2019, I had my first dermatology appointment about Accutane and met Dr. Cohen, one of the dermatologists at San Diego Family Dermatology. My mom was with me since she was hesitant about me taking isotretinoin. Dr. Cohen explained the whole process to me: monthly blood pregnancy tests (the first test at my initial appointment when I registered in iPLEDGE and the second test within the first 5 days of my menstrual period and at least 30 days after registering, and subsequent tests 3 to 4 days before my appointment at a clinical laboratory), other monthly laboratory studies, a urine pregnancy test during my monthly dermatologist appointments, registering in the iPLEDGE Program and monthly completion of the comprehension questions on the iPLEDGE Program website, keeping up with the dosing schedule every day, and monthly trips to the pharmacy to get the next month's prescription of the medicine. Dr. Cohen also explained the many risks and rules that came with isotretinoin. It was a lot of information and responsibility, but I was ready.

My isotretinoin acne treatment lasted about 5 months, from February 16 th to July 10 th. One month after starting isotretinoin, my face developed much larger and redder pimples; also, there were more lesions on my cheeks. I was not worried because I believed the medicine would eventually work by the end of the treatment. Besides, I was already used to prior acne treatments and being told that the worst comes first before getting better.
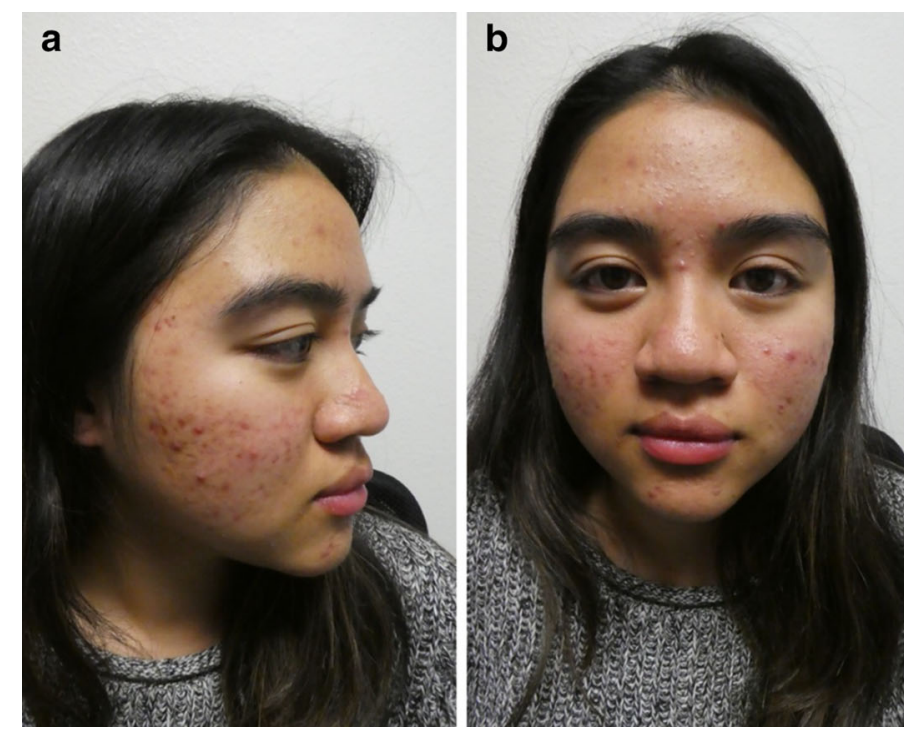

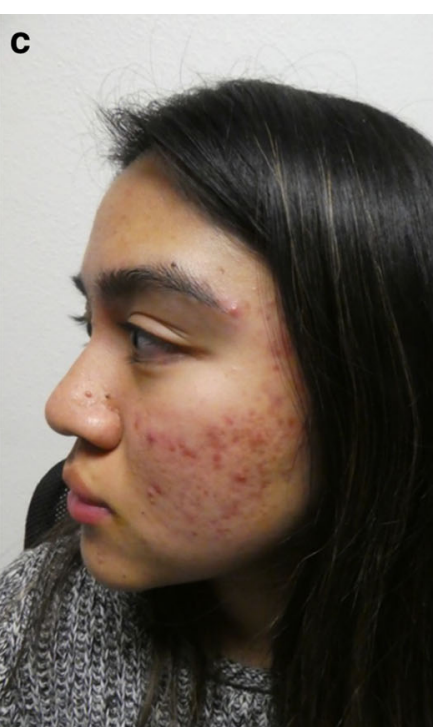

Fig. 1 A 19-year-old woman with severe and recalcitrant acne. Prior to treatment with isotretinoin, right side (a), frontal (b) and left side (c) views of her face show inflammatory papules and nodules, pustules, comedones and scarring on both cheeks 

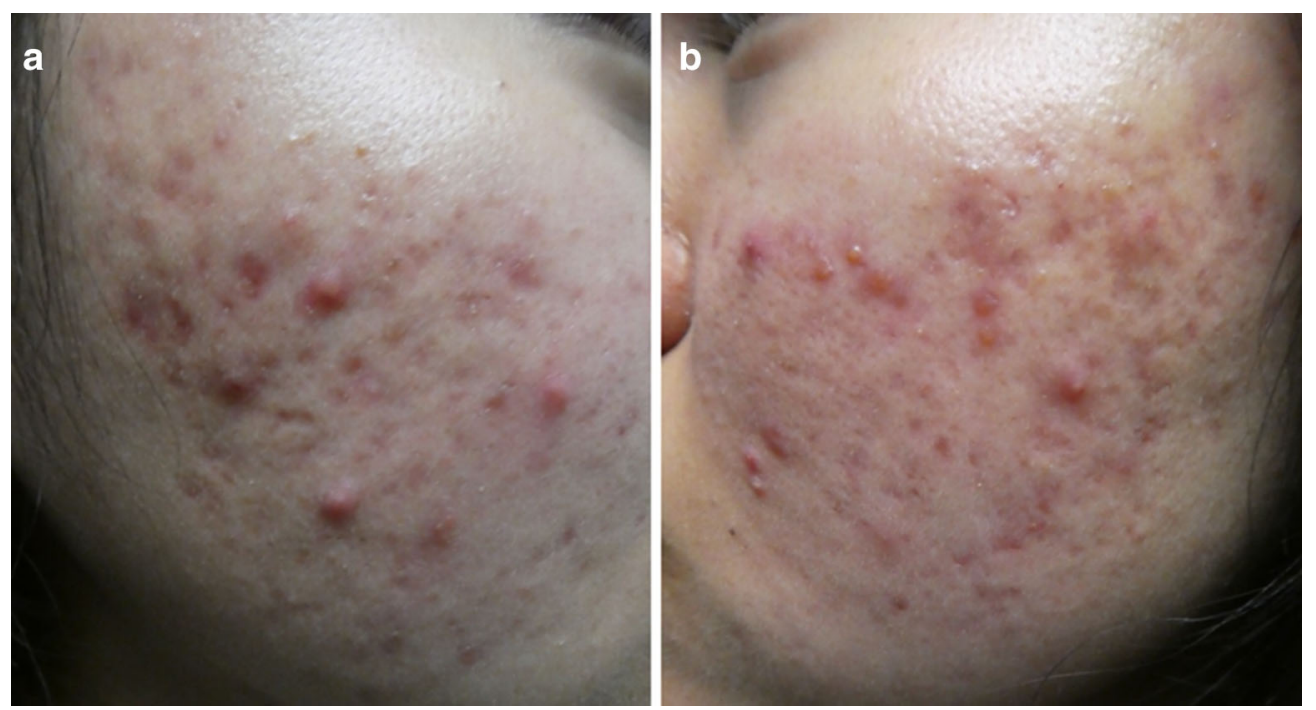

Fig. 2 Closer views of the right (a) and left (b) cheeks prior to isotretinoin therapy. In addition to erythematous atrophic scars on her bilateral malar cheeks, there are pustules and inflammatory papules and nodules

I kept an album on my phone for selfies I took every other day while on isotretinoin so I could see my progress over time. This is why I was surprised to see how bad my skin was when I first started the medicine. However, I eventually noticed that my forehead and chin were beginning to clear up.

By April 2019, the number of pimples on my cheeks was decreasing as well. Although my cheeks were still as red, they were actually clearing up. This was wonderful and the improvement seemed to be happening quickly. Previously, my cheeks were occupied by red pimples; now the acne lesions were fewer and scattered.

By May 2019, my skin was the clearest I had seen it in such a long time; this is what I had expected from the information I had seen online. However, there were the occasional one or two pimples that popped up - especially if I felt too stressed with school. Also, I still had the scars from past pimples; however, they were all tiny in comparison to the miraculous change that had occurred on my face.

I graduated community college on May 24th, and I felt invincible. I was proud of my accomplishments at school and completing a semester where I had tried new things. However, I felt even better knowing my skin looked great. I felt confident. My clearer skin reinforced the positivity and pride I felt from getting my degree and being accepted to continue my college studies at San Diego State University.

By June 2019, I only had one blemish on my skin. By July 2019, I had none. Dr. Cohen told me I would have to do one more serum pregnancy test and an additional appointment to evaluate my skin after being off isotretinoin for at least 4 weeks.

I returned for my August 2019 appointment. My skin had remained almost completely clear (Figs. 3 and 4). However, I noticed that small pimples only appeared if I was stressed or was just not taking care of myself. I realized, throughout this entire process, that I could not just rely on the medicine. I felt that I also had to consciously do my part and that I needed to deliberately contribute to my treatment.

To do this, I decided to drink about $65-85 \mathrm{oz}$ of water every day. I was assisted in this task with the help of an app called Plant Nanny. Every time I drank water, I had to not only log the amount of water, but also water a virtual plant. This would keep the plant and the rest of my virtual garden alive. I think that maintaining my hydration helped me to combat the isotretinoin-related dryness. 

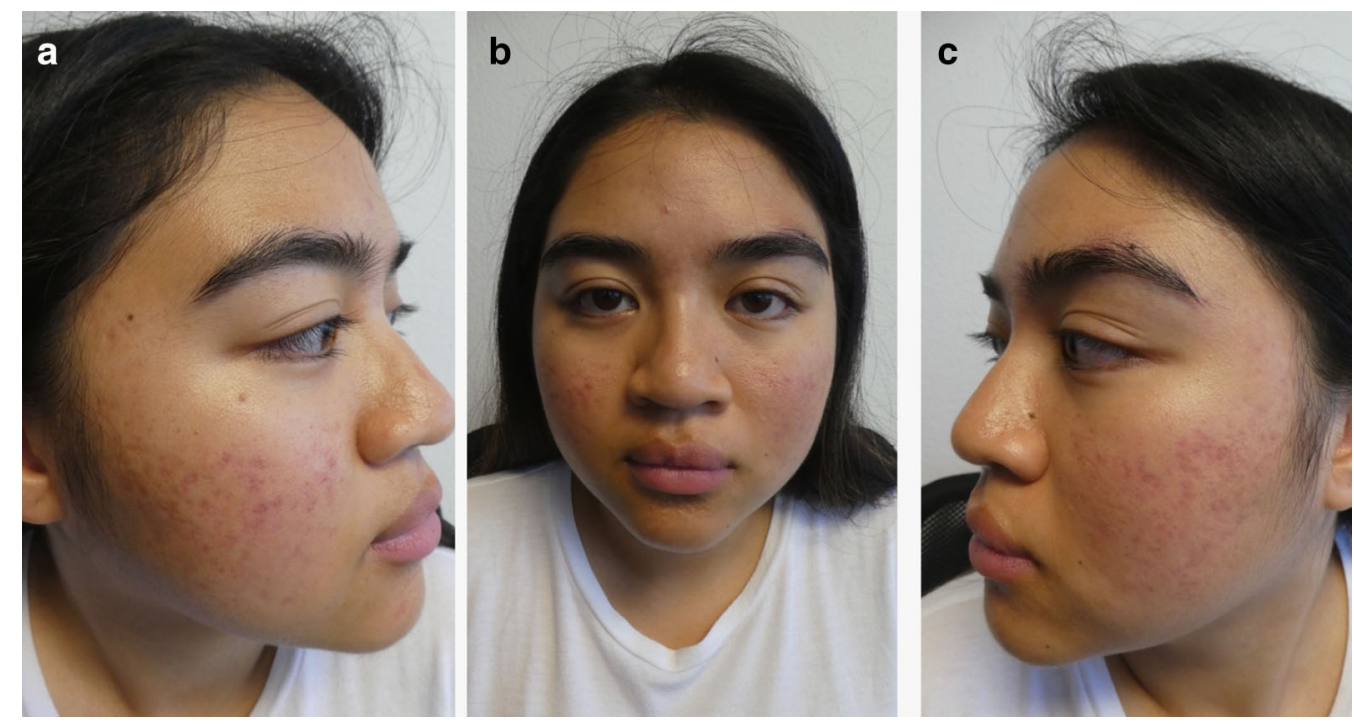

Fig. 3 Resolution of acne after 5 months of isotretinoin therapy. The right side (a), frontal (b) and left side (c) views of the woman's face shows essentially complete

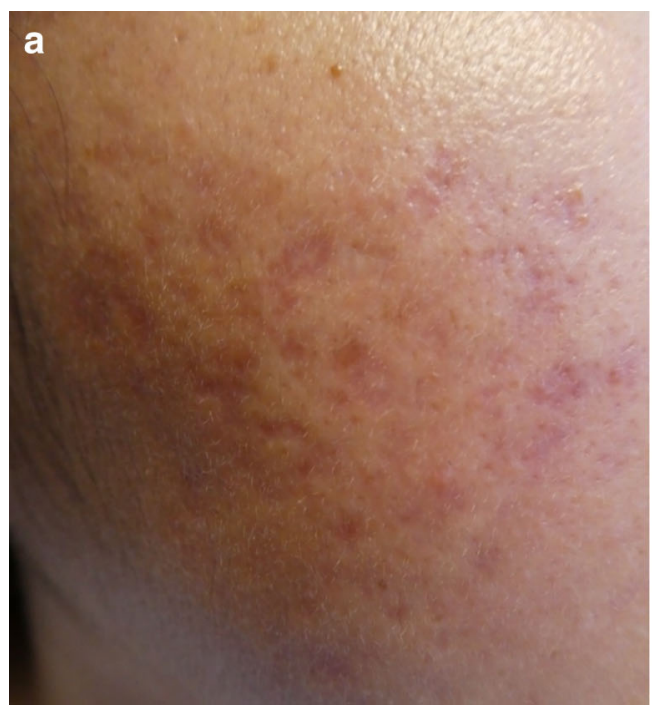

Fig. 4 Closer views of the right (a) and left (b) cheeks after treatment with isotretinoin for 5 months. She received $40 \mathrm{mg}$ daily of isotretinoin the first month and $60 \mathrm{mg}$ daily of tretinoin for the second thru fifth months

I also forced myself to sleep better. This didn't always mean going to sleep earlier. It meant that I would go to sleep without taking the stress of school and day-to-day occurrences to bed with me. clearing of her acne lesions. There is a single papule on her forehead. The scars on her cheeks are less prominent

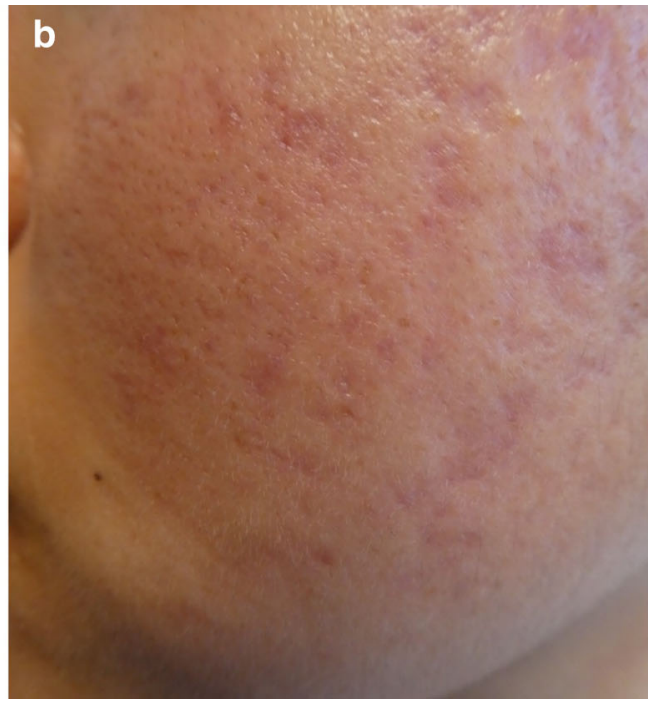

of treatment. The scars on her bilateral cheeks are less erythematous. Inflammatory and comedonal acne lesions are absent

When I woke up each morning, I reminded myself that I could handle the daily stress of my classes, projects, presentations and exams. Also, I looked forward to being present in class and I felt more comfortable talking to my classmates and professors. Before, I was anxious all of the 
time; now I was confident that I would not disappoint myself or others.

I realize that correlation doesn't equal causation. However, my treatment with isotretinoin was definitely the principal factor that enabled me to physically and psychosocially become better; I am so very thankful! Indeed, I even got my first job while I was being treated with isotretinoin; I will be tutoring college students in psychology and writing. Although I believe this medicine would not have worked as well for me if I had not put in the effort to change my lifestyle, I am convinced that this therapy did so much for me on its own - just as I had hoped it would.

Since I had so much faith in this medicine from the start, my self-esteem continued to improve as long as I was still taking the pills every day. Even in February, when the worst of my skin came out and the medicine did not appear to be working, I suppose a placebo effect took place and I felt like it was working.

My self-esteem was no longer as low as it used to be. I no longer neglected or avoided new classes, people or activities. Indeed, I was taking new classes, meeting new classmates and professors, and finally going to new events.

I was showing my face more often, and I did not feel afraid or ashamed. I felt happier and more confident, especially while taking the kickboxing classes twice a week and yoga class once a week; I had never previously been athletic in my life. Similarly, I was participating in class discussions; I had rarely voluntarily done that before. This was a huge turnaround for me.

I was very fortunate to have had a relatively smooth journey with isotretinoin. For the most part, the drug-associated side effects that I experienced were not like those I had read about and watched online. The main and only side effect that I experienced from isotretinoin was dryness.

At the beginning, my nose dried up enough to get occasional nosebleeds, but that stopped early on. In contrast, my lips were so dry throughout the entire treatment process that I was applying petrolatum to them almost every hour, every day. After a few months of treatment my eyes also became so dry that I had to completely stop wearing contacts and only wear glasses.

Although these side effects were all nuisances, they were minor. I felt I was lucky to only be experiencing these problems from the medicine. I had read and heard about other people suffering from far worse isotretinoin-related side effects: nausea and vomiting, bone and joint pain, decreased night vision, itchy scalp, hair loss or thinning, and depressive or suicidal thoughts.

I would like to think my skin finally became tired of fighting me and just responded to the treatment with isotretinoin. I appreciate Dr. Cohen and San Diego Family Dermatology; my dermatologist and the office staff were all very helpful and supportive to me. I am so glad that Dr. Cohen started me on this medication and made sure I was doing okay every month.

I had acne for so many years. In order to ensure that isotretinoin worked its best on me, I made several changes in myself and my life. I now drink lots of water, keep my lips moisturized, stay more physically fit (than I used to be), and allow myself to try new things. This month I will begin not only my first job as a tutor, but also my first day at San Diego State University. I will be starting with the clearest skin I have ever had in my life, and the most confidence I have ever felt.

\section{PHYSICIAN'S PERSPECTIVE}

Acne vulgaris, usually referred to as acne, is a very common skin condition [1]. However, the clinical presentation of acne can vary and there are several potential treatment modalities available for patients. This article does not contain any new studies with human or animal subjects performed by any of the authors.

Acne lesions include comedones (open comedones are referred to as black heads and closed comedones are referred to as white heads), papules and pustules, and nodules and cysts. Scarring (which can be atrophic or hypertrophic) may appear at prior lesion sites. Lesions typically appear on the face; however, the chest, back and proximal arms are also common sites [2-4]. 
A standardized classification or grading system for acne does not exist. The American Academy of Dermatology classified acne into mild, moderate and severe [1]. The United States Food and Drug Administration (FDA) recommended an Investigator Global Assessment scale with grades from 0 (clear skin) to 4 (severe); intermediate grades include 1 (almost clear), 2 (mild severity) and 3 (moderate severity) [4].

Acne is an inflammatory condition of the skin that affects the pilosebaceous follicle. Its pathogenesis is multifactorial. The key components include follicular hyperkeratinization, inflammation, Propionibacterium acnes (more recently also referred to as Cutibacterium acnes) bacteria colonization, and sebum production $[2,3,5,6]$.

Diet has also been shown to influence the development of acne. In addition to consumption of saturated fats, diets consisting of dairy products (including milk) and foods with a high glycemic index (such as baked potatoes, candy, couscous, French fries, high sugar beverages, low-fiber cereals that are high in added sugar, sweetened fruit juices, white pasta, and white rice) have been associated with acne [7-12]. Acne development has also been observed in individuals attempting to build muscle and/or gain weight by ingesting whey protein supplements $[13,14]$.

The management of acne is guided by the severity and extent of the lesions. The potential risk for acne scarring can be minimized by early and effective treatment. The approach to treatment may include topical therapies, systemic antibiotics, hormonal agents, isotretinoin and miscellaneous therapies. Monotherapy or treatment regimens that include a combination of these modalities may be utilized $[1,2]$.

Topical therapies include azelaic acid, antimicrobials (such as benzoyl peroxide, clindamycin, dapsone and erythromycin), retinoids (such as tretinoin which is also referred to as trans-retinoic acid, adapalene and tazarotene) and salicylic acid. Several vehicles can be utilized to deliver the agent: bar, cream, foam, gel, lotion, pad, pledget, solution and wash. Concurrent topical treatment with benzoyl peroxide and a retinoid should be considered as first-line therapy for most individuals with comedonal acne and/or inflammatory acne; in addition, topical therapy with a retinoid - with or without benzoyl peroxide - should be used for maintenance therapy for most patients with acne $[1-4,12]$.

The development of antibiotic resistance may occur when topical antibiotics are used as monotherapy. However, combinations of benzoyl peroxide with either an antibiotic (clindamycin or erythromycin) or a retinoid (adapalene) are available for treating acne. However, some of the topical therapies should not be used at the same time. For example benzoyl peroxide can result in oxidation and degradation of the isotretinoin molecule. Also, temporary orange discoloration of the skin and hair can occur if benzoyl peroxide and dapsone are used at the same time $[1,3,4,15]$.

Systemic antibiotics are used in the management of not only moderate to severe acne but also inflammatory acne that is resistant to topical therapies; they are usually prescribed in combination with benzoyl peroxide and/or a topical retinoid. Tetracyclines (such as doxycycline, minocycline and tetracycline) and macrolides (such as erythromycin and, less frequently, azithromycin) are the mainstay agents used to treat acne. However, other antibiotics such as trimethoprim (with or without sulfamethoxazole), penicillins (such as amoxicillin) and cephalosporins (such as cephalexin) have also been used to treat patients with acne $[1,3,4,12]$.

Adverse events may occur in individuals receiving systemic antibiotics. Photosensitivity is a common side effect of tetracyclines; in addition, these antibiotics should not be used in women who are pregnant and children less than 9 years of age. Also, the development of bacterial resistance is a concern when systemic antibiotics are prescribed; therefore, it would be optimal to limit their use to the shortest possible duration (such as 3 to 4 months) necessary to successfully treat the patient's acne $[1,3,4,12]$.

Hormonal agents for acne include combined oral contraceptive pills (which contain both an estrogen and a progestin component) and spironolactone. The FDA has approved the 
following oral contraceptive pills as second-line therapy in adolescent or adult women: ethinyl estradiol-norgestimate, ethinyl estradiolnorethindrone acetate and ethinyl estradioldrospirenone. Similar to combined oral contraceptive pills, the birth control patch (ethinyl estradiol plus norelgestromin) can also be effective for women with acne; however, higher rates of unintended pregnancies have been observed in heavier women (weighing more than $198 \mathrm{lb}$ or $90 \mathrm{~kg}$ ) using the patch for contraception $[1,2,4,16]$.

Certain medications used to treat bacterial or fungal infection can reduce the effectiveness of combined oral contraceptives when taken concomitantly - the antibiotic rifampin and the antifungal griseofulvin. Combined oral contraceptives can also be associated with drug-related adverse effects such as androgenic effects (hirsutism and worsening of acne depending on the progestin component), bloating, decreased libido, nausea, and vomiting. In addition, systemic adverse events that have been linked to combined oral contraceptives include cancer (such as a higher incidence of breast and cervical carcinoma), cardiovascular problems (such as myocardial infarction), stroke and thromboembolism (deep venous and pulmonary) $[1,2,4]$.

Spironolactone is effective in treating hormonally mediated acne in women. However, it is an aldosterone receptor antagonist and can cause hyperkalemia; indeed, a recent study has shown that hyperkalemia after initiating spironolactone was more common in women between 46 and 65 years of age compared to those in the 18- to 45-year age group [17]. Therefore, routine monitoring of serum potassium may not be necessary in healthy women age 45 years or less who do not have renal disease and who are not taking potassium-sparing diuretic agents $[2,17,18]$.

Spironolactone adverse events may include breast tenderness and menstrual irregularities. In addition, it is contraindicated during pregnancy since feminization of a male fetus may occur. A third-generation or fourth-generation combined oral contraceptive is often prescribed to women being treated with spironolactone to ameliorate drug-induced side effects and to prevent pregnancy [19-21].

In addition to conventional treatments of acne, there are several alternative therapies that can be used for the adjuvant management of this condition. Some of these therapies include herbal agents and spices, intralesional corticosteroids, chemical peels, light devices and lasers. Topical or systemic curcumin (or turmeric) has been used to treat acne $[1,12,22-24]$.

An individual inflammatory papule, nodule or cyst, may be clinically treated by injecting a low concentration - such as $3 \mathrm{mg} / \mathrm{ml}$ - of triamcinolone acetonide either into and/or adjacent and beneath the lesion; flattening occurs in 2 to 3 days. Chemical peels (using either glycolic acid or salicylic acid) may be useful for treating comedonal acne. However, chemical peels should not be performed in patients with active infection or open wounds or who have received isotretinoin therapy within the prior 6 months [1, 12, 25-28].

Photodynamic therapy (utilizing topical 5-aminolevulinic acid and intense pulsed blue or red light) may be effective in moderate to severe acne. Phototherapy using a combined blue-red light-emitting diode can be performed at home; it safely and effectively treats mild to moderate acne by attenuating inflammatory cell infiltration, decreasing sebaceous gland size and reducing sebum production. Several lasers have also been demonstrated to be beneficial in the treatment of acne: carbon dioxide, erbiumglass, infrared, potassium titanyl phosphate, and pulsed dye lasers [1, 12, 29-33].

Isotretinoin is an oral systemic retinoid that has resulted in a significant therapeutic advancement for the treatment of acne. It can be used as first-line therapy in the management of severe nodulocystic acne. In addition, it is indicated for the treatment of recalcitrant acne that has failed oral antibiotics in combination with topical benzoyl peroxide and retinoids. Many of the acne patients who are potential candidates for isotretinoin also have severe scarring as a consequence of their acne lesions $[1,4,12,34,35]$.

Isotretinoin effectively targets all aspects of acne pathogenesis; it decreases not only keratinocyte proliferation and thereby reduces 
follicular hyperkeratinization, but also inflammation, the growth and colonization of Propionibacterium acnes, and sebum production by the sebaceous glands. An $80 \%$ to $90 \%$ reduction in inflammatory lesions occurs after a complete course of isotretinoin. However, $20 \%$ to $30 \%$ of isotretinoin-treated patients may develop recurrence of their acne that is severe enough to require additional therapy, including another course of isotretinoin $[1,2,12,34]$.

Acne patients in whom treatment with isotretinoin is being considered should be screened for depression and inflammatory bowel disease. Although the evidence regarding an association between isotretinoin and depression is contradictory, worsening depression and suicidal ideation have been described in some patients on isotretinoin; therefore, counseling and monitoring patients taking isotretinoin for depression at each visit may be prudent. Similarly, the causal association between isotretinoin and inflammatory bowel disease (including ulcerative colitis and Crohn's disease) is unclear; indeed, some investigators have observed an increased risk of developing ulcerative colitis in patients being treated with isotretinoin [1, 2, 12, 34, 35].

Isotretinoin is a potent teratogen. Spontaneous abortion is estimated to occur in $50 \%$ of isotretinoin-exposed pregnancies and cardiovascular and/or skeletal defects are estimated to occur in $25 \%$ of pregnant women who have been exposed to isotretinoin. Currently in the United States of America, iPLEDGE is the FDAmandated risk-management program for pregnancy prevention (http://www.ipledgeprogram. com). Isotretinoin can only be prescribed by clinicians who are registered in iPLEDGE and written informed consent must be obtained by all patients who are going to be treated with isotretinoin [1, 2, 12, 34].

The patient taking isotretinoin is also required to register in iPLEDGE. Patients of childbearing potential must specify and use two forms of contraception; in addition, pregnancy tests (on the initial office visit or registration visit, again within the first 5 days of their menstrual period - and at least 30 days after registration - before starting the drug, each month during drug treatment and 1 month after stopping the drug) are required. In addition, both the clinician and patient must update the iPLEDGE site each month confirming the two forms of contraception and that the patient will neither share the medication nor donate blood during treatment or for 1 month after therapy has stopped $[1,2,12,34]$.

In addition to pregnancy testing for patients of child bearing potential, laboratory monitoring for patients being treated with isotretinoin traditionally included baseline and monthly evaluation of complete blood cell counts including platelets, serum chemistries [particularly liver function tests - aspartate aminotransferase (AST, also referred to as serum glutamic-oxaloacetic transaminase, SGOT) and alanine aminotransferase (ALT, also referred to as serum glutamic-pyruvic transaminase, SGPT) - and less commonly kidney function tests [blood urea nitrogen (BUN) and creatinine], and lipid profile [including cholesterol - total, high density lipoprotein (HDL) and low density lipoprotein (LDL) - and triglycerides] [1]. Recent studies have recommended less frequent follow-up laboratory studies and possibly adding gamma-glutamyl transferase (GGT) to monitor liver function and creatine kinase (CK) to monitor muscle damage [36-38]. In addition, an investigation has shown significantly increased plasma homocysteine levels and significantly decreased folic acid levels in patients after isotretinoin therapy; the relevance of the former and whether supplementation should be initiated for the latter remain to be determined [39].

The goal cumulative dose of isotretinoin is based on the patient's weight; current guidelines suggest a cumulative dose between 120 to $150 \mathrm{mg} / \mathrm{kg}$. Often, only half or two-thirds of the daily dosage is given for the initial and possibly second month of treatment before increasing to the standard daily dosage of $1 \mathrm{mg} / \mathrm{kg}$; therefore, approximately 5 months is necessary to reach the calculated cumulative dose. The daily dosage of isotretinoin is usually divided into a morning and evening dose; since the medication readily dissolves into fat, it is best absorbed when taken with food $[1,12]$.

The most common mucocutaneous side effects to isotretinoin include dryness of the 
skin and mucosa of the lips, nose, and eyes. Topical agents should be initiated for xerosis (using moisturizing lotion or cream), cheilitis (applying over-the-counter lip balms), rhinitis sicca and nose bleeds (using over-the-counter saline nasal spray) and keratoconjunctivitis sicca (using over-the-counter artificial tear drops). Patients may not be able to wear contacts on their eyes during isotretinoin treatment [1].

Earlier experiences with isotretinoin raised concerns regarding wound healing and the development of keloids in individuals who had procedures while on isotretinoin or after discontinuation of the drug [40]. However, more recent reviews suggest that - with the exception of ablative laser resurfacing and dermabrasion - cosmetic procedures or skin surgery or wisdom teeth extraction do not need to be avoided during or immediately after treatment with isotretinoin [41-44]. Yet, delay of these elective procedures for 6-12 months after completion of isotretinoin therapy - if possible - should be considered [1].

Laser in situ keratomileusis (LASIK) and photorefractive keratectomy (PRK) are not recommended to be performed during isotretinoin therapy or within 6 months after completion of treatment $[45,46]$. Also, isotretinoin should not be prescribed until 6 months following LASIK surgery [47]. However, recent studies are questioning these current guidelines [45, 48].

\section{MY PATIENT}

Nicola was a 19-year-old Filipino woman when I met her in January 2019. She was in her second year of community college and was majoring in psychology. Her mother had accompanied her to the appointment.

Nicola had a history of recalcitrant acne. Her acne was predominantly inflammatory with intermittent episodes of nodules and cysts. She had prominent scarring on her cheeks from her previous acne lesions.

Topical interventions to treat her acne had not been successful. Similarly, she had not improved with oral antibiotics or a combination oral contraceptive pill containing ethinyl estradiol and norgestimate.

We briefly talked about treatment options. Nicola had no history of either depression or inflammatory bowel disease. Her family doctor had suggested the possibility of isotretinoin. Therefore, when I suggested isotretinoin for the treatment of her acne she enthusiastically agreed.

I discussed potential adverse events that she should expect including dryness of the lips, nasal mucosa and possibly eyes. Other possible side effects such as muscle and joint pain, mood change and hair loss were also mentioned. In addition, I explained that she could not share any of the medication and could not donate blood while taking the medication (and for a month after her last dosage). Finally, I also stressed that isotretinoin was a teratogen, and she would need to use a second form of contraception (besides the birth control pill she was already taking) during treatment and for a month after completion of therapy if she chose to engage in sexual activity.

Nicola understood all of her responsibilities including checking in with the iPLEDGE web site each month. She signed the iPLEDGE agreement. A urine pregnancy test, performed in the office, was negative. Baseline laboratory studies (complete blood cell counts, serum chemistries including liver function tests, lipid tests including cholesterol and trigylceride, and a serum pregnancy test) to be performed at least 30 days later (and within the first 5 days of her menstrual period) were ordered.

Nicola began isotretinoin after the February office visit. Her total dosage was based on her weight: $120 \mathrm{mg}$ per $\mathrm{kg}$. She took $40 \mathrm{mg}$ daily for the first month and then $60 \mathrm{mg}$ daily thereafter.

Each month Nicola had her laboratory studies performed a few days before her office visit; the urine pregnancy test was repeated in the office. Each month I would monitor her progress and discuss any symptoms from the isotretinoin. I would also reinforce that she neither share the medication nor give blood while taking the drug or for 1 month after therapy had ended. In addition, after reviewing the two forms of contraception she was using, 


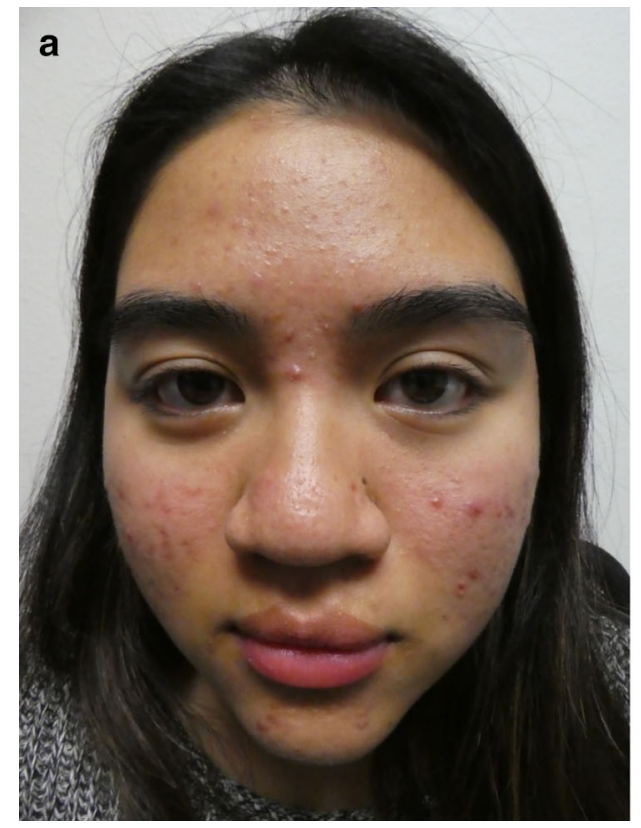

Fig. 5 Comparison of frontal views of the face prior to (a) and following (b) treatment with isotretinoin for 5 months. There has been significant improvement of her

both of us contacted the iPLEDGE web site and confirmed this information.

Nicola tolerated the isotretinoin well. During the first month taking the medication, she had nose bleeds; subsequently, these occurred less frequently. Her lips were very dry and she frequently applied Vaseline to them. She was not able to tolerate her contact lenses and had to wear glasses.

Nicola completed treatment with isotretinoin in July 2019. She returned to the office 1 month later; her laboratory studies were still satisfactory, and the serum pregnancy test was negative. Clinical photographs had been taken prior to starting isotretinoin; they were taken again 1 month after completing therapy (Fig. 5). There had been a significant improvement of her acne; her face was clear of acne lesions, except for a small papule on her forehead. The erythematous acne scarring on her cheeks was still present, but not as red as before she had started the drug.

Indeed, Nicola's efficacious clinical results secondary to isotretinoin therapy were dramatic. However, it was not until after reading

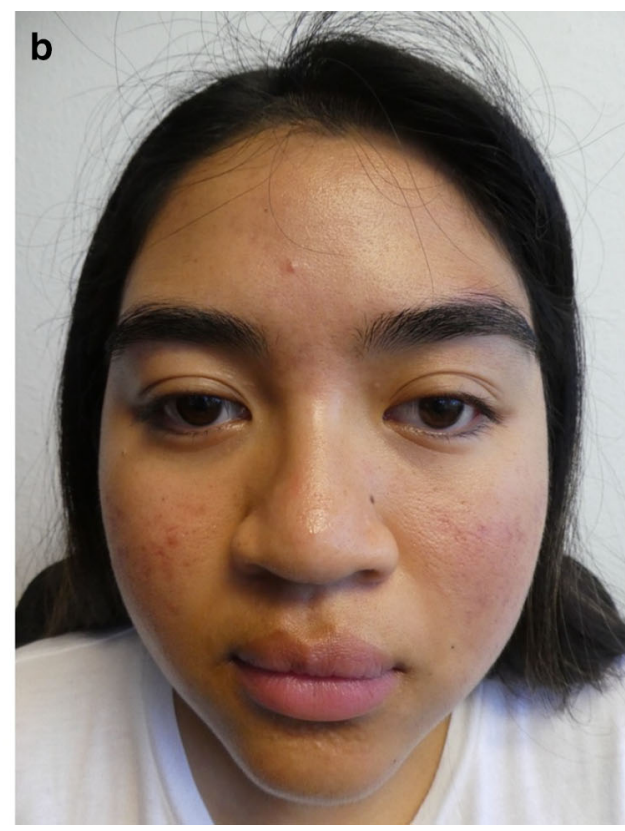

acne with resolution of nearly all inflammatory and comedonal lesions. Her malar scars are less erythematous and less prominent

Nicola's 'experience' that she shared in this paper that I became aware of the extent of the positive impact that this treatment had for her. I had no idea how devastating acne was to her - not only physically but also emotionally. I also did not realize the degree to which acne had altered the perception she had of herself and the manner in which she conducted her life. I am truly pleased that I was able to not only resolve Nicola's acne but also significantly improve her self-esteem and outlook toward life.

\section{ACKNOWLEDGEMENTS}

We thank the participant of the study.

Funding: The authors are fully responsible for all content and editorial decisions and received no financial support or other form of compensation related to the development of this manuscript. No funding was received for publication of this article. 
Authorship. All named authors meet the International Committee of Medical Journal Editors (ICMJE) criteria for authorship of this manuscript, take responsibility for the integrity of the work as a whole, and have given final approval for the version to be published. The opinions expressed in the manuscript are those of the authors.

Disclosures. Nicola I. Espinosa has nothing to disclose. Philip R. Cohen is a member of the journal's Editorial Board.

Compliance with Ethics Guidelines. Informed consent for publication of the images within the article was obtained from the patient.

Peer Review. Please note, contrary to the journal's standard single-blind peer review process, as a commentary this article underwent review by a member of the journal's Editorial Board.

Data Availability. Data sharing is not applicable to this article as no data sets were generated or analyzed during the current study.

Open Access. This article is distributed under the terms of the Creative Commons Attribution-NonCommercial 4.0 International License (http://creativecommons.org/licenses/ by-nc/4.0/), which permits any noncommercial use, distribution, and reproduction in any medium, provided you give appropriate credit to the original author(s) and the source, provide a link to the Creative Commons license, and indicate if changes were made.

\section{REFERENCES}

1. Zaenglein AI, Pathy AI, Schlosser BJ, Alikhan A, Baldwin HE, Berson DS, Bowe WP, Graber EM, Harper JC, Kang S, Keri JE, Leyden JJ, Reynolds RV, Silverberg NB, Gold LFS, Tollefson MM, Weiss JS, Dolan NC, Sagan AA, Stern M, Boyer KM, Bhushan R. Guidelines of care for the management of acne vulgaris. J Am Acad Dermatol. 2016;74(6):945-73.

2. Zaenglein AL. Acne vulgaris. $\mathrm{N}$ Engl J Med. 2018;379(14):1343-52.
3. Mwanthi M, Zaenglein AL. Update in the management of acne in adolescence. Curr Opin Pediatr. 2018;30(4):492-8.

4. Thiboutot DM, Dreno B, Abanmi A, Alexis AF, Araviiskaia E, Cabal MIB, Bettoli V, Casintahan F, Chow S, da Costa A, Ouazzani TE, Goh C-L, Gollnick HPM, Gomez M, Hayashi N, Herane MI, Honeyman J, Kang S, Kemeny L, Kubba R, Lambert J, Layton AM, Leyden JJ, Lopez-Estebaranz JL, Noppakun N, Ochsendorf F, Oprica C, Orozco B, Perez M, PiqueroMartin J, See J-A, Auh DH, Tan J, Lozada VT, Troielli $P$, Xiang LF. Practical management of acne for clinicians: an international consensus from the global alliance to improve outcomes in acne. J Am Acad Dermatol. 2018;78(2 Suppl):S1-23.

5. Kircik LH. Advances in the understanding of the pathogenesis of inflammatory acne. J Drugs Dermatol. 2016;15(1 Suppl 1):s7-10.

6. Zeichner JA. Inflammatory acne treatment: review of current and new topical therapeutic options. J Drugs Dermatol. 2016;15(1 Suppl 1):s11-6.

7. Cordain L, Lindeberg S, Hurtado M, Hill K, Eaton SB, Brand-Miller J. Acne vulgaris: a disease of Western civilization. Arch Dermatol. 2002;138(12):1584-90.

8. Adebamowo CA, Spiegelman D, Berkey CS, Danby FW, Rockett HH, Colditz GA, Willett WC, Holmes MD. Milk consumption and acne in teenage boys. J Am Acad Dermatol. 2008;58(5):787-93.

9. Melnik BC. Linking diet to acne metabolomics, inflammation, and comedogenesis: an update. Clin Cosmet Investig Dermatol. 2015;8:371-88.

10. LaRosa CL, Quach KA, Koons K, Kunselman AR, Zhu J, Thiboutot DM, Zaenglein AL. Consumption of dairy in teenagers with and without acne. J Am Acad Dermatol. 2016;75(2):318-22.

11. Burris J, Rietkerk W, Shikany JM, Woolf K. Differences in dietary glycemic load and hormones in New York City adults with no and moderate/severe acne. J Acad Nutr Diet. 2017;117(9):1375-83.

12. Oon HH, Wong S-N, Wee DC, Cheong WK, Goh $\mathrm{CL}$, Tan HH. Acne management guidelines by the dermatological society of Singapore. J Clin Aesthet Dermatol. 2019;12(7):34-50.

13. Silverberg NB. Whey protein precipitates moderate to severe acne flares in 5 teenaged athletes. Cutis. 2012;90(2):70-2.

14. Cengiz FP, Cevirgen Cemil B, Emiroglu N, Gulsel Bahali A, Onsun N. Acne located on the trunk, whey protein supplementation: is there any association? Health Promot Perspect. 2017;7(2):106-8. 
15. Del Rosso JQ, Pillai R, Moore R. Absence of degradation of tretinoin when benzoyl peroxide is combined with an optimized formulation of tretinoin gel $(0.05 \%)$. J Clin Aesthet Dermatol. 2010;3(10):26-8.

16. Rice C, Thompson J. Selecting and monitoring hormonal contraceptives: an overview of available products. US Pharm. 2006;6:62-70.

17. Thiede RM, Rastogi S, Nardone B, Sadowsky LM, Rangel SM, West DP, Schlosser BJ. Hyperkalemia in women with acne exposed to oral spironolactone: a retrospective study from the RADAR (Research on Adverse Drug events And Reports) program. Int J Woman's Dermatol. 2019;5(3):155-7.

18. Plovanich M, Weng QY, Mostaghimi A. Low usefulness of potassium monitoring among healthy young women taking spironolactone for acne. JAMA Dermatol. 2015;151(9):941-4.

19. Isvy-Joubert A, Nguyen JM, Gaultier A, Saint-Jean M, Le Moigne M, Boisrobert E, Khammari A, Dreno B. Adult female acne treated with spironolactone: a retrospective data review of 70 cases. Eur J Dermatol. $2017 ; 27(4): 393-8$.

20. Charny JW, Choi JK, James WD. Spironolactone for the treatment of acne in women, a retrospective study of 110 patients. Int J Womens Dermatol. 2017;3(2):111-5.

21. Grandhi R, Alikhan A. Spironolactone for treatment of acne: a 4-year retrospective study. Dermatology. 2017;233(2-3):141-4.

22. Vaughn AR, Branum A, Sivamani RK. Effects of turmeric (Curcuma longa) on skin health: a systematic review of the clinical evidence. Phytother Res. 2016;30(8):1243-64.

23. Panahi Y, Fazlolahzadeh O, Atkin SL, Majeed M, Butler AE, Johnston TP, Sahebkar A. Evidence of curcumin and curcumin analogue effects in skin diseases: a narrative review. J Cell Physiol. 2019;234(2):1165-78.

24. Yang MY, Chang KC, Chen LY, Hu A. Low-dose blue light irradiation enhances the antimicrobial activities of curcumin against Propionibacterium acnes. J Photochem Photobiol B. 2018;189:21-8.

25. Handog EB, Datuin MS, Singzon IA. Chemical peels for acne and acne scars in Asians: evidence based review. J Cutan Aesthet Surg. 2012;5(4):239-46.

26. Kaminaka C, Uede M, Matsunaka H, Furukawa F, Yamomoto Y. Clinical evaluation of glycolic acid chemical peeling in patients with acne vulgaris: a randomized, double-blind, placebo-controlled, split-face comparative study. Dermatol Surg. 2014;40(3):314-22.

27. Atorzi L, Brundu MA, Orru A, Biggio P. Glycolic acid peeling in the treatment of acne. J Eur Acad Dermatol Venereol. 1999;12(2):119-22.

28. Levesque A, Hamzavi I, Seite S, Rougier A, Bissonnette R. Randomized trial comparing a chemical peel containing a lipophilic hydroxy acid derivative of salicylic acid with a salicylic acid peel in subjects with comedonal acne. J Cosmet Dermatol. 2011;10(3):174-8.

29. Mei X, Shi W, Piao Y. Effectiveness of photodynamic therapy with topical 5-aminolevulinic acid and intense pulsed light in Chinese acne vulgaris patients. Photodermatol Photoimmunol Photomed. 2013;29(2):90-6.

30. Kwon HH, Lee JB, Yoon JY, Park SY, Ryu HH, Park BM, Kim YJ, Suh DH. The clinical and histological effect of home-use, combination blue-red LED phototherapy for mild-to-moderate acne vulgaris in Korean patients: a double-blind, randomized controlled trial. Br J Dermatol. 2013;168(5):1088-94.

31. Alexiades M. Laser and light-based treatments of acne and acne scarring. Clin Dermatol. 2017;35(2):183-9.

32. Wiznia LE, Stevenson ML, Nagler AR. Laser treatments of active acne. Lasers Med Sci. 2017;32(7):1647-58.

33. Rai R, Natarajan K. Laser and light based treatments of acne. Indian J Dermatol Venereol Leprol. 2013;79(3):300-9.

34. Bauer LB, Ornelas JN, Elston DM, Alikhan A. Isotretinoin: controversies, facts, and recommendations. Expert Rev Clin Pharmacol. 2016;9(11):1435-42.

35. Vallerand IA, Lewinson RT, Farris MS, Sibley CD, Ramien ML, Bulloch AGM, Patten SB. Efficacy and adverse events of oral isotretinoin for acne: a systematic review. Br J Dermatol. 2018;178(1):76-85.

36. Lee YH, Scharnitz TP, Muscat J, Chen A, GuptaElera G, Kirby JS. Laboratory monitoring during isotretinoin therapy for acne: a systematic review and meta-analysis. JAMA Dermatol. 2016;152(1):35-44.

37. Hansen TJ, Lucking S, Miller JJ, Kirby JS, Thiboutot DM, Zaenglein AL. Standardized laboratory monitoring with use of isotretinoin in acne. J Am Acad Dermatol. 2016;75(2):323-8.

38. Webster GF, Webster TG, Grimes LR. Laboratory tests in patients treated with isotretinoin: 
occurrence of liver and muscle abnormalities and failures of AST and ALT to predict liver abnormality. Dermatol Online J. 2017;23(5):1-3.

39. Kim HJ, Lee SM, Lee JS, Lee SY, Chung EH, Cho MK, Lee SH, Kim JE. Homocysteine, folic acid, and vitamin B12 levels in patients on isotretinoin therapy for acne vulgaris: a meta-analysis. J Cosmet Dermatol. 2019. https://doi.org/10.1111/jocd. 13059 .

40. Zachariae H. Delayed wound healing and keloid formation following argon laser treatment or dermabrasion during isotretinoin treatment. Br J Dermatol. 1988;118(5):703-6.

41. Guadanhim LR, Goncalves RG, Bagatin E. Observational retrospective study evaluating the effects of oral isotretinoin in keloids and hypertrophic scars. Int J Dermatol. 2016;55(11):1255-8.

42. Sharma J, Thiboutot DM, Zaenglein AL. The effects of isotretinoin on wisdom tooth extraction. J Am Acad Dermatol. 2012;67(4):794-5.

43. Spring LK, Krakowski AC, Alam M, Bhatia A, Brauer J, Cohen J, Del Rosso JQ, Diaz L, Dover J, Eichenfield LF, Gurtner GC, Hanke CW, Jahnke MN, Kelly KM, Khetarpal S, Kinney MA, Levy ML, Leyden J, Longaker MT, Munavalli GS, Ozog DM, Prather H, Shumaker PR, Tanzi E, Torres A, Velez MW, Waldman $\mathrm{AB}$, Yan AC, Zaenglein AL. Isotretinoin and timing of procedural interventions: a systematic review with consensus recommendations. JAMA Dermatol. 2017;153(8):802-9.
44. Waldman A, Bolotin D, Arndt KA, Dover JS, Geronemus RG, Chapas A, Iyengar S, Kilmer SL, Krakowski AC, Lawrence N, Prather HB, Rohrer TE, Schlosser BJ, Kim JYS, Shumajker PR, Spring LK, Alam M. ASDS guidelines task force consensus recommendations regarding the safety of lasers, dermabrasion, chemical peels, energy devices, and skin surgery during and after isotretinoin use. Dermatol Surg. 2017;43(10):1249-62.

45. Mahadevappa $\mathrm{OH}$, Mysore V, Viswanath V, Thurakkal S, Majid I, Talwar S, Aurgangabadkar SJ, Chatterjee M, Bhat MR, Barua S, Ganjoo A. Surgical outcomes in patients taking concomitant or recent intake of oral isotretinoin: a multicentric study-ISOAIMS study. J Cutan Aesthet Surg. 2016;9(2):106-14.

46. Bower KS, Woreta F. Update on contraindications for laser-assisted in situ keratomileusis and photorefractive keratectomy. Curr Opin Ophthalmol. 2014;25(4):251-7.

47. Miles S, McGlathery W, Abernathie B. The importance of screening for laser-assisted in situ keratomileusis operation (LASIK) before prescribing isotretinoin. $\mathrm{J}$ Am Acad Dermatol. 2006;54(1):180-1.

48. Ortega-Usobiaga J, Llovet-Osuna F, Djodeyre MR, Bilbao-Calabuig R, Gonzalez-Lopez F, Llovet-Rausell A, Druchkiv V. Outcomes of laser in situ keratomileusis and photorefractive keratectomy in patients taking isotretinoin. Am J Ophthalmol. 2018;192:98-103. 